\title{
Introduction to Section II
}

\author{
Peter Shea \\ Editor-in-Chief, Online Learning \\ University at Albany, State University of New York
}

This issue of $O L J$ also includes 11 articles from our regular submission process. These articles discuss a broad range of themes, including Massive Open Online Courses (MOOCs), gamification, new approaches to online course development, and online discussion and interaction. We also include a book review in Section II of this issue.

The first of our MOOC articles is "Instructional Strategies That Respond to Global Learners' Needs in Massive Open Online Courses" by Trang Phan of Fresno State University. MOOCs attract a global audience with various cultural, linguistic, and economic backgrounds and, thus, require faculty and staff teaching and designing these courses to learn to respond to diverse student populations. In this paper the author explores MOOC instructors' and designers' perceptions of multicultural learners in a wide variety of MOOC courses as well as students' learning needs and behaviors. The paper investigates how the perceptions of faculty and staff were reflected in the design phase and identifies the various challenges encountered in implementing instructional strategies to respond to learners' needs. The author concludes that certain elements of MOOC design were responsive to diverse learners' needs, including course components that provided assignment submission language choices and content materials categorized by level of difficulty for learners of different language backgrounds and educational levels. This study provides insights about more culturally sensitive course design to future MOOC creators in a globally connected world.

The second paper focusing on MOOCs is "Small Groups in a Social Learning MOOC (slMOOC): Strategies for Fostering Learning and Knowledge Creation" by Marianne Krasny of Cornell University; Bryce DuBois of the Rhode Island School of Design; Mechthild Adameit, an Independent Consultant from Uruguay; Ronnie Atiogbe from the University of Lomé, Togo; Muhammad Lukman Baihaqi Alfakihuddin of Indonesian Biodiversity and Conservation; Tergel Bold-erdene from Ulaanbaatar Broadcasting System, Mongolia; Zahra Golshani from the University at Albany, State University of New York; Rodrigo González-González from the National Autonomous University of Mexico; Ishmael Kimirei of Tanzania Fisheries Research Institute; Yamme Leung of the World Wide Fund for Nature, Hong Kong; Lo Shian-Yun of National Taiwan Normal University; and Yue Yao of World Animal Protection, Beijing. This paper is a qualitative case study of small groups in a MOOC called Environmental Education: Transdisciplinary Approaches to Addressing Wicked Problems offered by Cornell University. The authors describe this course as an "slMOOC" (social learning MOOC), falling between cMOOCs, characterized by highly self-directed learning, and xMOOCs, which have more structure and conventional assessments. The course included small groups that met in person and were facilitated by group leaders. The methods include a survey and interviews of the group leaders, which inquire about their motivations for taking on that role as well as outcomes resulting from leading a group. The researchers also looked at barriers to learning that were experienced and efforts to address them. Together, this and the preceding paper advance our understanding of how 
we may support more effective learning in international multicultural settings through close examination of online facilitator and learner behaviors, challenges, and strategies for overcoming these.

The next paper is "Meaningful Gamification and Students' Motivation: A Strategy for Scaffolding Reading Material" by Lynette Tan Yuen Ling of National University of Singapore. This study examines more recent conceptualizations in the field of research on games and learning, applying the notion of meaningful gamification to a flipped classroom setting. Central to the study and to meaningful gamification are Deci and Ryan's theories of intrinsic motivation and the key components of competency, relatedness, and autonomy. The author hypothesizes that meaningful gamification can be used to enhance these elements of intrinsic motivation to encourage students to complete out-of-class learning tasks (i.e., prereading) to improve in-class discussions and activities. Quantitative results suggest that the approach is more engaging than other kinds of academic tasks measured on the same scales used here. Qualitative methods disclosed both positive and negative student reactions to the use of a game to support prereading. Importantly, the authors conclude that students' comprehension of the material improved. The paper offers pathways for future studies, potentially with larger samples, and other research methods that would more clearly determine specific elements of meaningful gamification that can improve learning in both blended and online environments.

The fourth paper in this section is "Online Course Design and Development Among College and University Instructors: An Analysis Using Grounded Theory" by Sally Baldwin, YuHui Ching, and Norm Friesen of Boise State University. The purpose of this study is to understand how instructors design online courses at public four-year colleges and universities using a method reflecting authentic practice. Methods include interviews with 14 instructors who design and teach online courses applying a grounded theory approach. The authors are ultimately interested in how the practice of instructional design for online learning can be theorized. The paper concludes that despite the widespread understanding of instructional design principles in higher educational settings, participants approached online course design as a problem to be solved based on whatever informal resources were immediately available. The participants did not see course design as a specialized process requiring expert guidance or design-specific resources, such as guidebooks. Paradoxically, interviewees did report that they spontaneously followed a process similar to the ADDIE instructional design model. This was the case even among participants who are instructors of instructional design. The study includes a depiction of the authors' "Informal Design Theory: A Process Model of Instructors Creating Online Courses." Understanding the process that many faculty informally follow has numerous benefits for the practice of online course design and, ultimately, institutional capacity to support faculty in improving online learning.

The next paper is "Students' Perceptions of Quality Across Four Course Development Models" by Victoria Brown and Mario Toussaint of Florida Atlantic University and David Lewis of the University of Miami. As in the previous paper, the focus of this study is understanding and improving processes of online course design. Here the authors investigate varying levels of support for faculty, including no support (except financial), a course training, a supplementary workshop on the Quality Matters standards, and an instructional-designer-supported model. The researchers collected survey data to assess students' perceptions of the relative quality of courses developed through each of these models. The most highly rated courses were developed through the instructional-designer-supported model, which include a course template to facilitate 
development. This paper provides clarity regarding the comparative merits of different faculty development models commonly used for online course design.

Keeping with the theme of faculty development, the following paper is "Educators' Preparation to Teach, Perceived Teaching Presence, and Perceived Teaching Presence Behaviors in Blended and Online Learning Environments" by Lisa Gurley of William Carey University. In this paper the author argues that faculty development preparing faculty to teach online impacts the quality of instruction provided in blended and online learning courses. Further, prior research indicates that instructional design and facilitation of productive discourse tailored specifically to the online environment (elements of teaching presence) are essential to supporting the goals of online instruction. To date, however, research has focused almost exclusively on student accounts of the quality of instructors' teaching presence. In this paper the author focuses instead on faculty perceptions of their own ability to engage in effective instructional design and facilitation based on the form of professional development they received. An adapted Community of Inquiry survey was used to assess faculty perceptions of teaching presence. The study finds a statistically significant difference between perceived ability to engage in effective facilitation for faculty that completed certification courses in preparation for teaching in blended and online learning environments, as compared to faculty that only received on-the-job training. Qualitative data supported this finding. The paper provides additional support for the need for quality faculty development, adding specificity with regard to the format of training that may be more effective for developing specific online instructional skills.

The seventh paper in this section is "Out-of-School Reading and Literature Discussion: An Exploration of Adolescents' Participation in Digital Book Clubs" by Jamie Colwell of Old Dominion University, Lindsay Woodward of Drake University, and Amy Hutchison of George Mason University. Building on New Literacies theory, the core of which is foundational work done by Gee, this study looks at new literacies, defined as the skills necessary for students to successfully navigate and engage in digital reading and writing practices. These practices differ from skills necessary for traditional paper-based reading and composition that define traditional literacy. Such skills are important to fostering more literate adolescents in the 21st century. Specifically, this study examines the new literacy practices exhibited by 13-to-17-year-olds in an online summer reading program and how such a program might inform more authentic opportunities for literacy engagement in school settings. The researchers use a general inductive qualitative approach to code the online interactions of the study's 12 participants. They conclude that the students spontaneously adopted online discussion practices that mixed formal and more personal forms of discourse to develop more affecting interaction through text. As teachers seek to encourage richer dialogue around literature, the study suggests that rather than using traditional approaches assigned in face-to-face discussions, educators might try asynchronous online forums. They observed that students in their study simultaneously adopted more complex and varied discussion techniques that featured more sophisticated transactions with the text. Future research might better articulate how best to facilitate these forums in formal educational settings to ensure all young students succeed in developing new literacies.

The next paper is "A Generalizable Framework for Multi-Scale Auditing of Digital Learning Provision in Higher Education" by Samuel Ross of the University of Leeds, Okinawa Institute of Science and Technology, and Trinity College Dublin, and Veronica Volz, Matthew K. Lancaster, and Aysha Divan of the University of Leeds. This study considers the provision of digital learning resources at an institutional level and whether equity in use of resources exists 
across various units. The researchers examine to what extent digital learning has been implemented across degree programs, program levels, and schools/colleges within the institution that serves as the case study; identify current gaps and how might they be reduced; and investigate how the results of this audit can be used to inform a digital or blended learning strategy for academic units. This study assists in assessing differences in access to learning resources between students (and discloses such differences across units within the institution studied here). The audit process described in this paper can surface potential issues in resource variability and promote discussion of how such issues might be resolved. For example, if only science students get access to new visualizations, simulations, or digital games, is that a problem? And if so, what should be done about it? As noted by the authors, however, each case will vary, and digital learning should be used only when pedagogically relevant. That said, given current trends in higher education, provision of digital resources will be a growing area of interest, and this paper contributes to our understanding of ways of assessing it.

The next paper is 'Undergraduate Kinesiology Students' Experiences in Online Motor Development Courses" by Takahiro Sato of Kent State University and Justin A. Haegele of Old Dominion University. The study employs a descriptive-qualitative methodology applying a case study design to uncover themes in the experience of online kinesiology students. The authors use open-ended interviews, bulletin board discussion logs, and online assessment projects as data to surface three themes: rigor and flexibility, importance of peer feedback, and the application of video assessment to support learning. The researchers conclude that the study demonstrated that undergraduate students can have positive and meaningful experiences when enrolled in an online life span motor development course, but care needs to be taken in the design of learning experiences for this population. This includes attention to program focus, student age, amount of prior online experience, and the design of assessments.

The tenth paper in this section is "The Impact of Program-Wide Discussion Board Grading Rubrics on Students and Faculty Satisfaction" by Brinda McKinney of Arkansas State University. The researcher notes that online discussion board activities can be confusing to students and daunting for faculty to facilitate and grade both fairly and efficiently. To address this issue, faculty participants in the study collaboratively developed a single, program-wide discussion board grading rubric that clearly outlined expectations for all students and offered consistent guidelines for faculty's assessment of online discussion activity. The rubric included evaluative criteria for initial post content, frequency of posts, follow-up post content, supportive references, and grammar. The rubric was implemented in each of the RN-BSN online courses in the program under investigation. After implementation of the rubric, faculty time spent grading discussions was reduced by more than $50 \%$. Students had substantially fewer complaints about grading as well. The paper includes the full rubric for reference and additional details on the benefits of a single, program-wide grading scheme.

The final paper here is Susan Ko's review of the new book Transactional Distance and Adaptive Learning: Planning for the Future of Higher Education by Farhad Saba, emeritus at San Diego State University, and Rick Shearer of Penn State University. The book takes up Michael Moore's well-known theory, applying it to a contemporary context. Ko gives us a good brief synopsis and helpful insights on the book's strengths and weaknesses.

Please read, discuss, and share these new studies and consider contributing to the scholarly dialogue supporting the future of Online Learning. 